history on the other side of the water. Our regret that $/$ stood, of course, that the judgment was not against! bright star Regulus, where it will remain apparently English locomotive engineers should be deprived of the validity of Mr. Maxim's patent. It decides that almost stationary among the stars during the latter these valuable records for use in their projected the patent is valid but that the government has not part of the month. Jupiter is splendidly placed now museum does not prevent us from expressing our satis- infringed. faction that the Field Museum, in Chicago, is proportionately enriched. The moral of the incident is that no time should be lost on either side of the water in gathering together the scattered remnants of draw ings, records, etc., which are liable to be lost or dethem to appreciate their intrinsic historical value.

THE JUDGMENT IN THE CORDITE CASE.

The celebrated cordite case, in which Mr. Hiram Maxim is suing the English government for infringement of his patent for the manufacture of smokeless and military world, and calls to mind the celebrated Nobel case of a few years previous. Mr. Maxim, who is one of the most successful inventors and manufacturers in the field of guns and explosives, is the inventor turers in the field of guns and explosives, is the inventor
of a smokeless powder which bears his name and is perhaps the most successful powder of its kind on the market to-day.

The English government is making and using a smokeless powder to which it has given the name of cordite. It closely resembles the Maxim powder, and so directly infringed some of the most important claims -f his patent that the patentee carried the matter to the because of the great celebrity of the plaintiff and the many millions of dollars which were involved in the many

Nitro-glycerine, as every one knows, is much too violent to be employed in firearms. If a gun should be loaded with a charge of dynamite and be set off with a fulminating cap in the ordinary way, instead of pro-

pelling the shot at a high velocity,
the gun and the shot into atoms.

Guncotton, that is, tri-nitro-cellulose, is also a very the residue dried, it may be employed in a gun when nearly in a dry state; that is, if it has about 2 per cent of acetone in the compound it holds its shape and may be used as a propellant in firearms, but it is apt to get be used as a propellant in firearms, but it is apt to get too dry. When the last vestige of solvent escapes, it
is very apt to crack, exfoliate, and become porous and scaly. In this condition it is too violent to use in a firearm. However, if a small portion of castor oil is mixed with the solvent, the solvent dries out and leaves tageously employed in almost its pure state. Camphor acts in the same manner as castor oil, but camphor evaporates after a time, leaving the cellulose in its pure state, when it becomes dangerous.

pure state, when it becomes dangerous.
Suppose now that a small quantity of nitro-glycerine, say 3 per cent or 4 per cent, is combined with the guncotton, it prevents it from getting too dry, and makes it burn very much slower ; in fact, nitro-glycerine may be said to "slow the mixture" until about 10 per cent is added.

In 1888 Hiram S. Maxim combined high grade guncotton, that is, the insoluble variety of tri-nitro-cellulose, with nitro-glycerine to form an explosive, but as it was dissolved in acetone. The acetone was then it was dissolved in acetone. The acetone was then evaporated out, leaving the compound nitro-glycerine and true guncotton, and, to insure a greater degree of
stability and uniformity in burning, various oils were stability and uniformity in burning, various oils were
experimented with. However, in the end castor oil was found, everything considered, to be preferable; so the next year another patent was taken out for a powder consisting of tri-nitro-cellulose, nitro-glycerine and a suitable oil.

The second claim of Mr. Maxim's patent is as follows : "The manufacture of an explosive compound by first dissolving guncotton by means of acetone or other solvent and then incorporating with the dissolved guncotton, nitro-glycerine or similar material and castor oil or ton, nitro-glycerine or similar material and castor oil o
other suitable oil substantially as hereinbefore deother su,

The English government had been using cylinder oil in place of castor oil, and to avoid the Maxim patent they called it "mineral jelly." Cylinder oil is the product of the same filtering process as is used in producing vaseline, and the government experts were making is the same. One witness claimed that the cylinder oil was used, not to moderate the explosion, but to lubricate the bore of the gun. The same witness for the government had previously testified that the oil was used to prevent detonation - this testimony having been given in the Nobel trial.

The judge gave judgment against the plaintiff. The burden of the judgment was to the effect that the cylinder oil which the government used was not an oil but a hydrocarbon, or at any rate that it could not be considered under the head of a "suitable oil." It was ment were different from those of Mr. Maxim, consequently they did not infringe in that respect; and yet it was admitted that according to the first claim of the
patent all proportions were included. It will be under-

\section{THE HEAVENS FOR APRIL.}

The sun's right ascension on the first of the month is $0 \mathrm{~h} .45 \mathrm{~m} .0 \mathrm{~s}$; ; and its declination north of the celestial equator 4 deg. $50 \mathrm{~m} .16 \mathrm{~s}$

On the last day of the month the sun's right ascension is $2 \mathrm{~h} .32 \mathrm{~m}$. $37 \mathrm{~s}$.; and its declination north $15 \mathrm{deg}$. $0 \mathrm{~m} .18$

Although we are now at the minimum period of the sun spot cycle, an occasional fine group may be seen. The great naked eye spot of January last, which was nearly 90,000 miles in length, appeared by rotation of
he sun in February and March, in accordance with the prediction, and will probably be again seen well adprediction, and will probably be again seen well adanced on the sun's disk on the first of April. At each
reappearance in February and March, the group had changed considerably in shape and was reduced in size, although visible to the naked eye through a smoked glass.

MERCURY.

Mercury on the first day of April, at 10 hours, is in with the earth and sun beyond the sun. Mercury
wion then changes from morning to evening star. This little world, about 3,000 miles in diameter, moves so it will reach its greatest elongation east of the sun, $20 \mathrm{deg} .43 \mathrm{~m}$. This will be the best time to look for
. The 20 deg. $43 \mathrm{~m}$. This will be the best time to look for
Mercury in the western evening sky, its northern declination being very favorable indeed. Another intersting fact, and one of great value in identifying this shy little planet, is that, at the time of its greatest elongation from the $s$

On April 17, at 4 hours, Mercury and Venus will be conjunction, when Mercury will be 5 e $13 \mathrm{~m}$. south of Venus.

The right ascension of Mercury on April 1 is $0 \mathrm{~h}$. $5 \mathrm{~m} .0 \mathrm{~s}$., and its declination north is $3 \mathrm{deg} .40 \mathrm{~m} .40 \mathrm{~s}$. On the last day of the month its right ascension is $3 \mathrm{~h}$. venus.

Venus is still our lovely evening star, and will continue as such through nearly the entire month. On April 28, at one o'clock, it comes into inferior conjunction with the sun and then changes to morning star. Its northern declination will keep it a conspicuous ob-
ject in the western evening sky during the early por ject in the western evening sky during the early por-
tion of the month. All should attempt to secure a telescopic view of Venus during the first week or two of April, for, seen in the telescope, it presents a most or three days old. The apparent diameter of the
or cusps will increase, while the crescent will become more slender until inferior conjunction.

The conjunction of Venus with Mercury on April 17 as been referred to in the section on Mercury.

On April 4, at 6 h. $52 \mathrm{~m}$., Venus will be in conjunction with the moon, when Venus will be 1 deg. $35 \mathrm{~m}$ north of the moon. Venus is stationary on April 6,
which means that its motion is in the line of sight, and which means that its motion is
in this case, toward the earth.

On the 1st of the month Venus crosses the meridian t $2 \mathrm{~h} .6 \mathrm{~m}$. in the afternoon, and sets at half past nine in the evening.

On the last of the month, being near to inferior con junction, Venus crosses the meridian and sets almost imultaneously with the sun.

The right ascension of Venus on April 15 is $2 \mathrm{~h} .43 \mathrm{~m}$. $47 \mathrm{~s}$, and its declination north 22 deg. $53 \mathrm{~m} .28 \mathrm{~s}$ MARS.

Mars is evening star, being somewhat west of overhead at early evening and in the constellation Gemini the Twins.

On April 8, at nine o'clock in the morning, there will be a very interesting conjunction of Mars and the third magnitude star Epsilon Geminorum, when
be only two minutes of are south of the star.

The nearest approach, occurring as it does in ful daylight, will only be observable in the telescope. But on the evening of April 7, before the conjunction, and on the evening of the 8 th, after the conjunction, the
tar and planet will be seen very close together. Their hange of position will also afford an interesting illus tration of the planet's orbital motion.

On April 9, at $3 \mathrm{~h}$. $52 \mathrm{~m}$., Mars is in conjunction with the moon, when the planet will be $50 \mathrm{~m}$. of are south of On April 16, at 8 h., Mars reaches its greatest helioentric latitude north.

On the first of the month Mars crosses the meridian at $5 \mathrm{~h} .41 \mathrm{~m}$. in the afternoon, and sets $1 \mathrm{~h} .20 \mathrm{~m}$. after midnight. On the last of the month Mars crosses the meridian at $4 \mathrm{~h} .47 \mathrm{~m}$. and sets $20 \mathrm{~m}$. after midnight. JUPITER. \begin{tabular}{c|l} 
JUPITER. & $\begin{array}{l}\text { given, but the performance was, in any case, very re- } \\
\text { Jupiter is well up in the eastern evening sky as soon } \\
\text { markable, and we agree with the writer that it was }\end{array}$
\end{tabular} exceedingly interesting, showing much complicated detail. The phenomena of its satellites will also prove of reat interest. Some instances here follow.

On the evening of April 4, at $8 \mathrm{~h}$. $38 \mathrm{~m}$., satellite I will enter upon the disk of Jupiter in transit. At $9 \mathrm{~h} .31 \mathrm{n}$. the shadow of satellite I will enter in transit. At $10 \mathrm{~h}$. $57 \mathrm{~m}$. the egress of satellite I will occur; and at $11 \mathrm{~h}$ $50 \mathrm{~m}$. the shadow of satellite I will pass off the disk. the disk of the planet in transit. At $11 \mathrm{~h}$. $39 \mathrm{~m}$. the satellite will leave the disk; and at $11 \mathrm{~h} .48 \mathrm{~m}$. the shadow will egress. On April16, at $7 \mathrm{~h} .55 \mathrm{~m}$., the shadow satellite II will enter upon the disk. At $8 \mathrm{~h} .40 \mathrm{~m}$. IV will reappear from an occultation. $22 \mathrm{~m}$. sa tellite Will reappear from an occultation. At $10 \mathrm{~h} .46 \mathrm{~m}$.
the shadow of satellite II will pass off the disk. On the shadow of satellite II will pass off the disk. On
April 13 at $5 \mathrm{~h} .56 \mathrm{~m}$. Jupiter is in conjunction with the moon, when the planet will be $3 \mathrm{deg} .8 \mathrm{~m}$. north of the moon. On April 1 Jupiter crosses the meridian at $9 \mathrm{~h}$.
$32 \mathrm{~m}$. P. M. and sets at $4 \mathrm{~h} .20 \mathrm{~m}$. A. M. On the last of the month it crosses the meridian at $7 \mathrm{~h} .34 \mathrm{~m}$. P. M. nd sets at $2 \mathrm{~h} .15 \mathrm{~m}$. A. M.

The right ascension of Jupiter at the middle of the deg. $32 \mathrm{~m} .38 \mathrm{~s}$.

SATURN

Saturn is morning star, rising, however, at $10 \mathrm{~h} .20 \mathrm{~m}$ M. at the opening of the month; very good obser ations may be had with the telescope after midnight. On the first of the month it is on the meridian at $3 \mathrm{~h}$ $\mathrm{m}$. A. M. The right ascension of Saturn on the fifteenth of the month is $15 \mathrm{~h} .51 \mathrm{~m} .51 \mathrm{~s}$; declination

URANUS AND NEP'TUNE.

Uranus is in Scorpio near its northwestern border. Its right ascension for the middle of the month is $15 \mathrm{~h}$. $44 \mathrm{~m} .15 \mathrm{~s}$; and its declination south $19 \mathrm{deg} .33 \mathrm{~m} .17 \mathrm{~s}$ Neptune is between the horns of Taurus. Its position for the middle of the month being, right ascension, $5 \mathrm{~h}$ m. $54 \mathrm{~s}$; declination north, 21 deg. $34 \mathrm{~m} .25 \mathrm{~s}$.

Smith Observatory, Geneva, N. Y., March 18, 1897.

\section{MAGNETIC METAL EXTRACTION}

Magnetic extraction of metals from ores is success fully practiced at the Franklin Furnace, New Jersey, described thus: There are three sets of the magnets, 74 in the first set, 320 in the second, and 320 in the third set. The magnets are about four feet long. and set. The magnets are about four feet long,
an its journeyings has to pass a mile of and the ore on its journeyings has to pass a mile of
faces of magnets. Right here is presented what to the faces of magnets. Right here is presented what to the The magnets are arranged in tiers of five in a tier. The top one is weak, but they increase in strength as they go down, until the bottom one is very powerful. The ward in front of the magnets. The magnets jerk the particles of iron oxide from the mass as they descend but the iron does not adhere to the magnets. And right here is a most surprising sight. The ore, in passing the first magnet, inclines toward it. As it rushes ing the first magnet, inclines toward it. As it rushe
down, the ore swings in more toward the magnets, un down, the ore swings in more toward the magnets, un-
til as it reaches the last one it curves inward and under it in a half circle, without any particle of ore adhering to the magnet. In the first passage past the magnet small quantities of stone stick to the ore. The ore is carried upward and started down before the second lot off the particles of stone. The first set of magnets ex tract 62 per cent of oxide of iron. When the mass has passed the second set of magnets, there is in it 75 per cent of oxide of iron. Then it is ground again and
passes the third and most powerful set of magnets, passes the third and most powerful set of magnets,
which takes the phosphates out and makes Bessemer of it. The percentage of iron oxide is then from 85

[McCaul's Factory,from which the above is taken,fails to state how much coal and how many horse power is required to crush a ton of the ore and operate all the
magnets used in the separation. The ScIENTIFIC magnets used in the separation. The $\mathrm{SC}$.
AMERICAN readers would like to know.-Ed.]

\section{RAPID BRIDGE ERECTION}

We have recently had occasion to make note of in stances of rapid bridge erection, and we are now in re most re, giving us the latest and in some respects the informed that at Vandreuil, Quebec, a place about twenty-five miles from Montreal, the Grand Trunk Railway Company recently took out a 98 foot iron span in the brief period of eight minutes, and erected a new one in its place in forty-seven minutes. The whole operation, including preliminary preparations, occupying only three hours. The weight of the bridge is not night. The structure of its wonderful belt system is

as it is dusk. It is in Leo, a few degrees east of the probably unprecedented. 